\title{
Communication
}

\section{Geological and Cultural Heritage: Dissemination Experiences in Tuscany}

\author{
Sonia La Felice ${ }^{1,2, *}$, Tsegaye Abebe ${ }^{3}$, Andrea Aquino ${ }^{4}$, , Simone Landi ${ }^{2}$, Marco Lezzerini ${ }^{4}$ (I) \\ and Claudia Principe 1,2 (D) \\ 1 Istituto di Geoscienze e Georisorse, Consiglio Nazionale delle Ricerche, \\ Via Giuseppe Moruzzi 1 - 56124 Pisa, Italy \\ 2 Associazione La Nuova Limonaia, c/o Museo di Storia Naturale, Università di Pisa, \\ via Roma 79 - 56011 Calci (PI), Italy \\ 3 Adhana Geological Consultancy Service, Via M.L. King 9 - 56021 Cascina (PI), Italy \\ 4 Dipartimento di Scienze della Terra, Università di Pisa, Via Santa Maria 53 - 56126 Pisa, Italy \\ * Correspondence: sonia.lafelice@igg.cnr.it
}

Received: 30 June 2019; Accepted: 23 July 2019; Published: 25 July 2019

\begin{abstract}
We report on some recent experiences of scientific dissemination activities on geomaterials carried out by a network of scientific organizations in Tuscany (Italy). The primary message we want to disseminate is that even the most "insignificant" rock (e.g., those constituting the bar or kitchen counter-tops) stores in their interior very useful information beyond the beautiful colors and their aesthetic appearance. These rocks can tell stories of very old geological periods on how they were formed. Their structures, texture and shape, as well as their chemistry and mineralogy provide clues to the reconstruction of geological events. Moreover, the rocks used in urban architecture and monuments are an inexhaustible archive containing a lot of historical and economic information on the development of a city and its surrounding area. The role of geologists, in this context, is to provide to the public, in clear and engaging language, the tools necessary to solve the puzzle (i.e., identify the most important types of rocks and rock-forming minerals, know their physico-chemical properties, their textures and structures and discover the environments in which they formed). A specific objective of this work is to stimulate an exchange between various research organizations (universities, public research institutions, museums, associations, etc.) and the civil society.
\end{abstract}

Keywords: building stone; geomaterials; urban petrography; cultural heritage; scientific dissemination; Tuscany; Italy

\section{Introduction}

\subsection{Public Perception of Geoscience}

Although the issues related to the past and the future of the Earth are crucial in the scientific debate and fundamental to building a sustainable development, the Earth Science studies at University level show a lack of appeal, with the number of students enrolled generally lower than the needs, even in the labor market. This situation is partly linked to the high school education curriculum, which is not very dense in Earth Science themes. Also, according to some studies, (see King, 2012 [1] and references therein) there are a number of difficulties encountered by students in learning geoscience, such as: (i) the memorization of complex terminologies, (ii) the spatial literacy, (iii) the three dimensional visualization, (iv) the understanding of depth of geological time as compared with humans relatively short existence, (v) the speed of processes-human observers may have difficulties perceiving changes in rocks and land features over time-and (vi) the abstract concepts, which are intangible, such as 
the structure of Earth's interior. In this regard, the Geological Society of America (GSA) released a position statement [2] in which it declared the importance of the teaching Earth Science at lower school level. The document also evidenced the importance of the Earth Science teacher's qualification, which constantly needs updating. Natural processes and resources affect our economy, our security and the sustainability of our environment and the GSA statement highlights the responsibility of the scientific community to transmit scientific knowledge and skills to citizens so that they can make more informed decisions.

In order to support and strengthen the existing institutions engaged in the dissemination of scientific culture, increase university enrollment in scientific courses, contribute to teacher training in developing innovative tools and methodologies to improve the teaching of Earth Science and student careers, the MIUR (Italian Minister of Education, University and Research) promotes national projects in which schools, universities and national research centers are involved (e.g., "Piano Lauree Scientifiche" [3], "Alternanza scuola-lavoro" [4], "Diffusione della cultura scientifica" (Lg. n.113/1991) [5], "Settimana della Cultura Scientifica e Tecnologica" [6]). In addition, the Italian Geological Survey promotes dissemination activities such as seminars and workshops including teaching courses at high school level, with the aim to promote Earth Sciences disciplines [7]. Furthermore, the European Commission support "European Researchers' Night" [8], a public event during which the researchers explain how they can contribute to the development of modern society. Moreover, various non-profit associations promoting scientific and technological culture operate in the national and regional territories (e.g., Ass. Settimana del Pianeta Terra [9], Ass. La Nuova Limonaia [10] and Ludoteca Scientifica (LUS) [11]).

\subsection{How to Attract Public Interest}

Rocks are perfect witnesses of geological events at different scales and of the Earth's history. In fact, rocks existed since the beginning of the Universe and will continue to exist in the future. For instance, meteorites are among the oldest rocks in the solar system and can tell us about the age and formation of the early Earth. Rocks store very useful information which provide evidence on how plate tectonic movements, volcanism, weathering and erosion agents have modified the planet for millions of years. They are the only long-lasting materials capable of recording information that allows us to reconstruct not only the Earth's history, but also the evolution of living beings (e.g., fossils) and of humans (e.g., artifacts, works of art). Due to this unique feature, we believe that rocks could be a good starting point for bringing the public closer to geology.

Tuscany is located in a geological, historical and cultural context that can provide a perfect setting for the staging of the "tale" that the rocks can tell us. In fact, Tuscany is one of the regions in Italy richest in natural stones. Apuan Alps (Figure 1), in particular are well known in the world for the most famous marbles quarries [12-14]. There are approximately 130 active quarries today, 2/3 of which are concentrated in the Carrara area.

The Apuo-Versilian district is highly active in the quarrying activity sector and world leading in marble and granite (rocks in general) cutting, carving and polishing technologies [15] (Figure 2). 


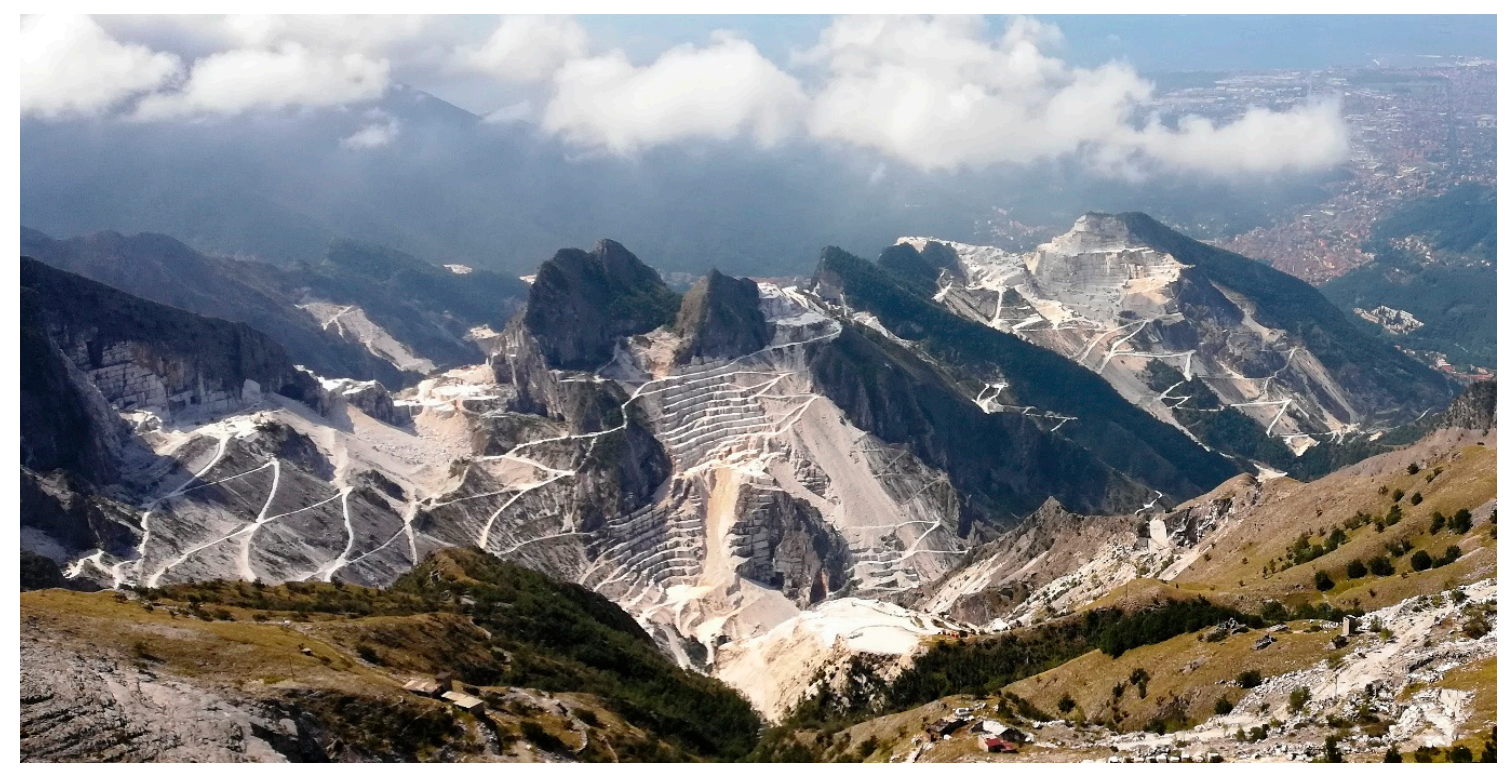

Figure 1. Panoramic view of the white marble quarries in the Apuan Alps (Carrara, Italy).

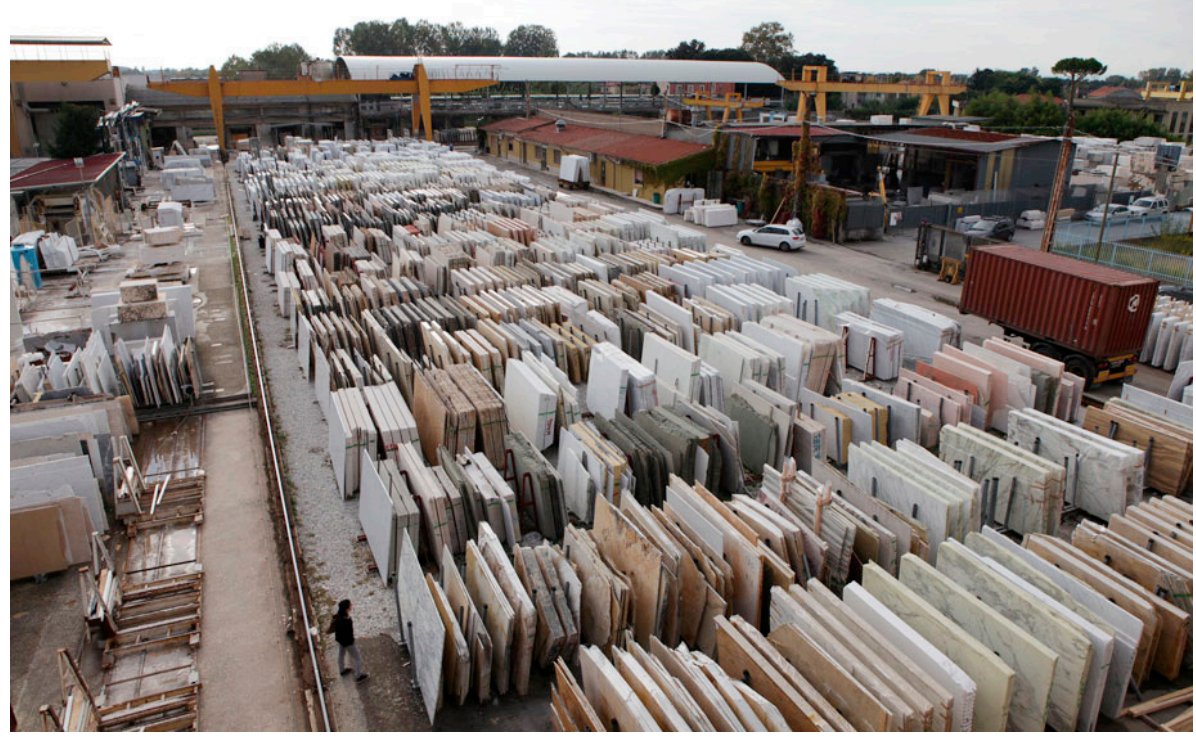

Figure 2. Overview of marble manufacturing plant, Savema S.p.a. at Pietrasanta (Lucca, Italy).

Also, the art and architecture of Tuscany have gone through an articulated and complex story, which commenced at the beginning of civilization and continued, without interruption, to the present day, through key periods such as the Roman era, the Middle Ages and the Renaissance (Figure 3). 

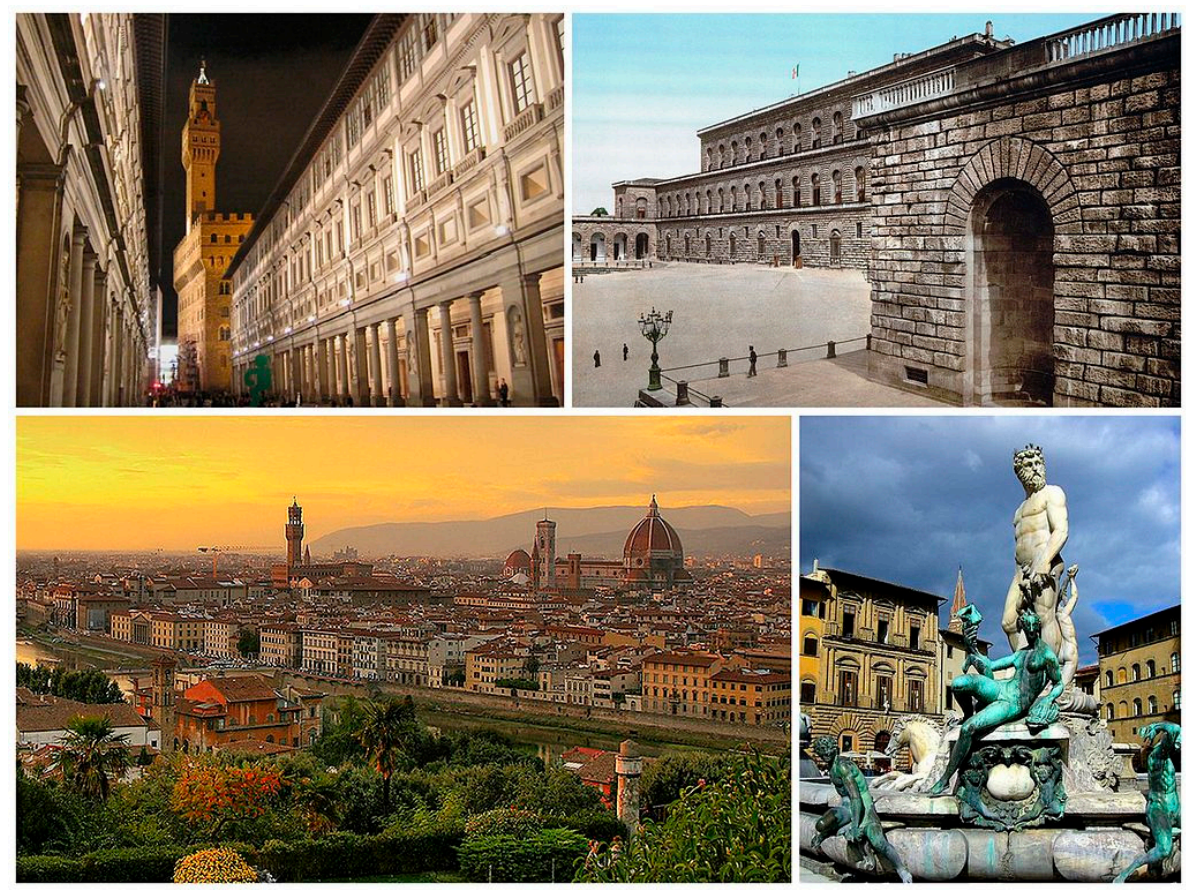

Figure 3. Views of Florence, main town of Tuscany (Italy). Examples of the widespread use of the ornamental stones in arts and architecture from historic buildings to marble statues. Image from: https://commons.wikimedia.org/wiki/File:Collage_Firenze.jpg.

Here, therefore, the public has the fortune of a great availability of rocks (both as a raw material and as a building material in the urban architecture and works of art), but generally appreciates them only from an aesthetical point of view and does not observe them through the eyes of a geologist. The role of a geologist, in this context, is to clearly communicate to non-scientists, including students, the importance of the geological heritage. To achieve this goal, it is necessary to use very attractive dissemination approaches that are able to lead visitors to live a direct experience. The geologist helps to closely observe the rocks and explaining their technical and physico-chemical properties allows the comprehension of complex rock formation processes that are otherwise difficult to imagine.

For our dissemination activities, we use the rocks that people find the most fascinating: the so-called ornamental stones, which are commonly used mainly in the fields of building, monumental and funerary. The commercial nomenclature of ornamental stones is increasingly abandoning any reference to their scientific classification by extensive use of imaginative and exotic names that not providing indications on the nature of the rocks and their places of origin, but are of considerable advertising effect (e.g., Emerald Pearl, Magic Black, Sky Gray, New Tropical, Tiffany) (Figure 4).

From a commercial point of view, the main characteristics that define an ornamental stone and its quality are represented by the color, the ability to be polished, the grain size, the texture, the mechanical resistance, the availability, the shape and dimensions of the extractable blocks. The commercial classification of stone materials is traditionally divided into four categories (Marbles, Granites, Stones, Travertines) codified by the UNI EN 12670:2019 standard [16]. The classification of rocks in these four major groups represents the division between "soft" and "hard" rocks, essentially differentiated on the basis of their different hardness when cutting and polishing regardless of their real geological origin. In fact, for example, in the group of "Marbles", all crystalline rocks that are as soft (Mohs hardness 3-4) as calcite, dolomite and serpentine, and could be easily polished, are included. Limestones, serpentinites, marble itself and many others "soft" rocks of metamorphic, igneous and sedimentary origins are included. Even the category of "Granites" include all phaneritic rocks that have a medium-high hardness (Mohs hardness 6-7), like quartz, feldspar and feldspatoid, and that are well polishable. Many metamorphic rocks such as gneisses, migmatites, pegmatites, beside a vast variety of igneous 
intrusive rock, from granite to gabbro, are also included in the "Granite" category. On the other hand, geological classification of rocks is based on their formation processes (igneous, metamorphic and sedimentary) and their composition and structure.
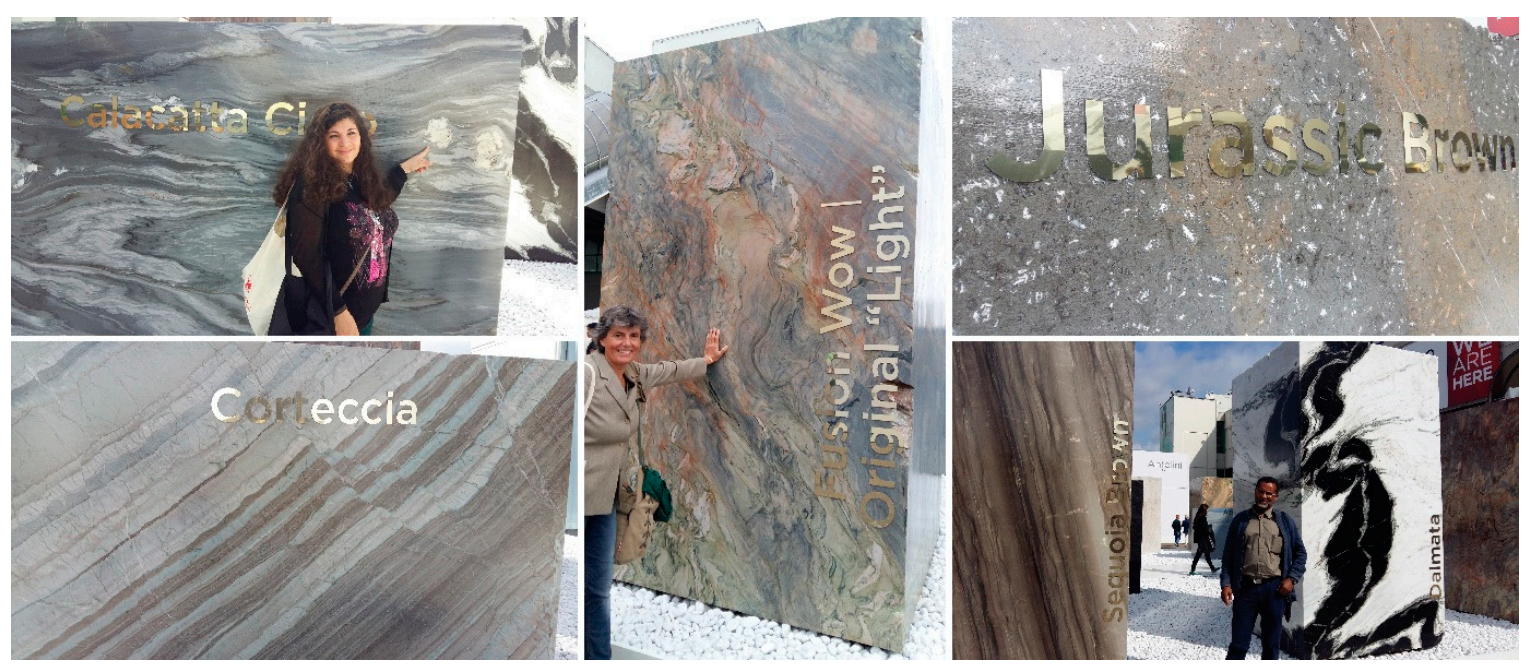

Figure 4. Examples of commercial fancy names of considerable advertising effectiveness (e.g., Calacatta Cielo, Corteccia, Fusion Wow, Jurassic Brown, Sequoia Brown and Dalmata). Large format of blocks at Marmomac International trade fair (Verona, Italy, 2015).

For the purpose of our work, we have collected over 400 types of ornamental stones mainly through donations from marble workers and companies operating in the stone industry of the Apuo-Versilian district, Verona district and other international companies contacted at international meetings for natural stone industry (e.g., Marmomac, Verona, Italy) (Figure 5).
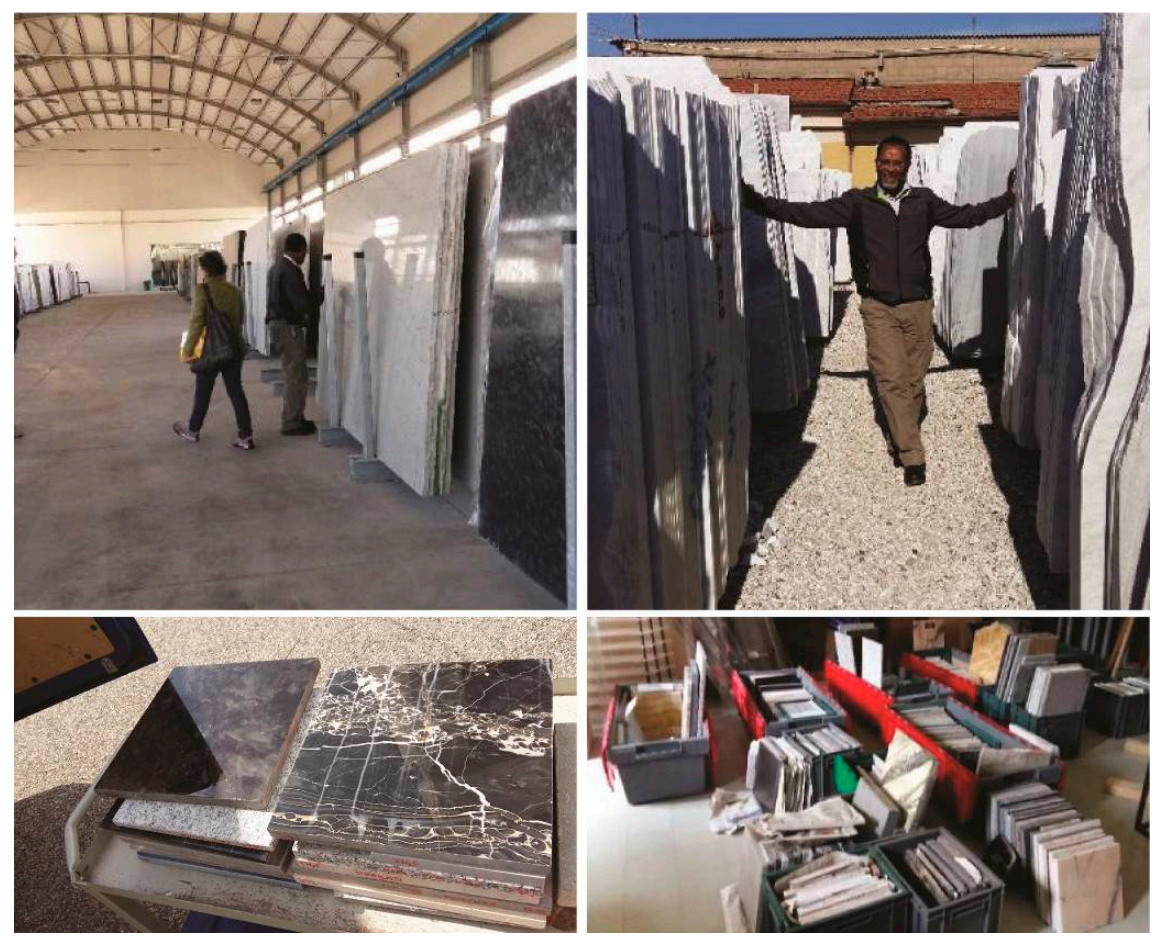

Figure 5. Selection, collection and storage stages of ornamental stone materials from marble companies of the Apuo-Versilian district. 
For some activities, we have been concerned with the rocks that are part of our architectural heritage, such as those used in historic buildings, churches and city walls. This is quite common in other countries. For instance, both in the U.S.A. and other European countries, universities commonly promote scientific tours to discover the geology of building stones in metropolitan areas $[17,18]$. Recently, the Department of Earth Sciences of the University of Turin (Italy) implemented a mobile application TOURinSTONE [19] to promote and enhance the urban geological heritage of Turin. The app is an interactive city map with 25 places, where historical and petrographic information is available, in order to present an overview of the main ornamental stones used in historic buildings, churches and city center streets.

\section{Disseminations Experiences}

We have experienced various type of outreach, training and dissemination activities, such as scientific exhibition with guided tours, thematic conferences, city walks, training courses and workshops. All the activities were open to students of all levels, including academic audiences, interested individuals and experts, and the audience was always very large. Some examples are illustrated below.

\section{1. "Anche le Pietre Parlano" Exhibition}

"Anche le Pietre Parlano" (i.e., Even the Stones Talk) was an exhibition hosted at Villa Borbone (Viareggio, LU) [20], conceived and realized by the Institute of Geoscience and Georesources (IGG-CNR), of some 400 specimens of rocks ( $30 \mathrm{~cm} \times 30 \mathrm{~cm}$ polished tiles) normally used as ornamental stones quarried from around the world and predominantly from Italy. The tiles are labeled with commercial name, scientific name, country of origin and age (where available) (Figure 6).

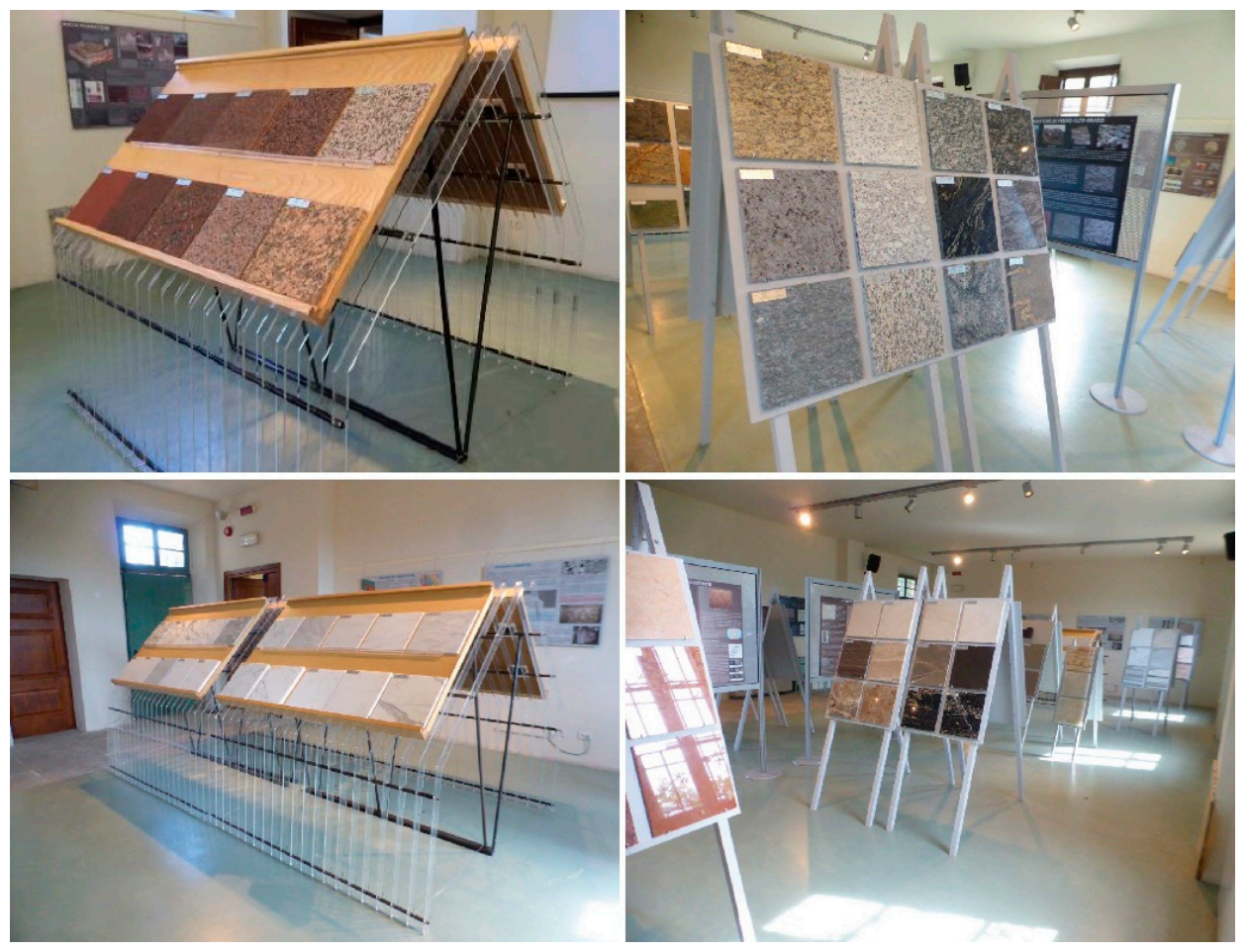

Figure 6. "Anche le pietre parlano" exhibition of over 400 polished tiles of ornamental stones hosted at Villa Borbone (Viareggio, Lucca). 
The exhibitions were supported by 20 explanatory panels, illustrating the petrogenetic processes, the scientific rock classification and specific references to some of the tiles on display (Figure 7); moreover, the visitors enjoyed an expert guided tour (Figure 8).
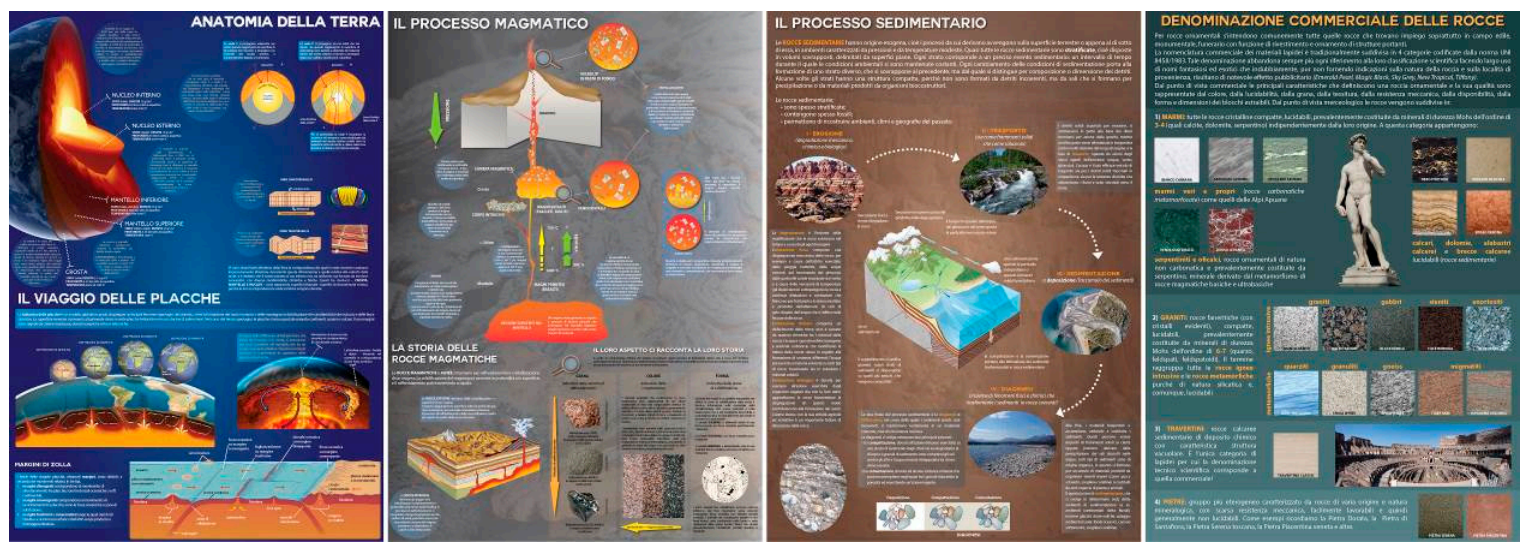

Figure 7. Some examples of panels used during the exhibition explaining the geological processes that take place on Earth and in particular, those that are directly linked to the formation of rocks exposed in the exhibition.
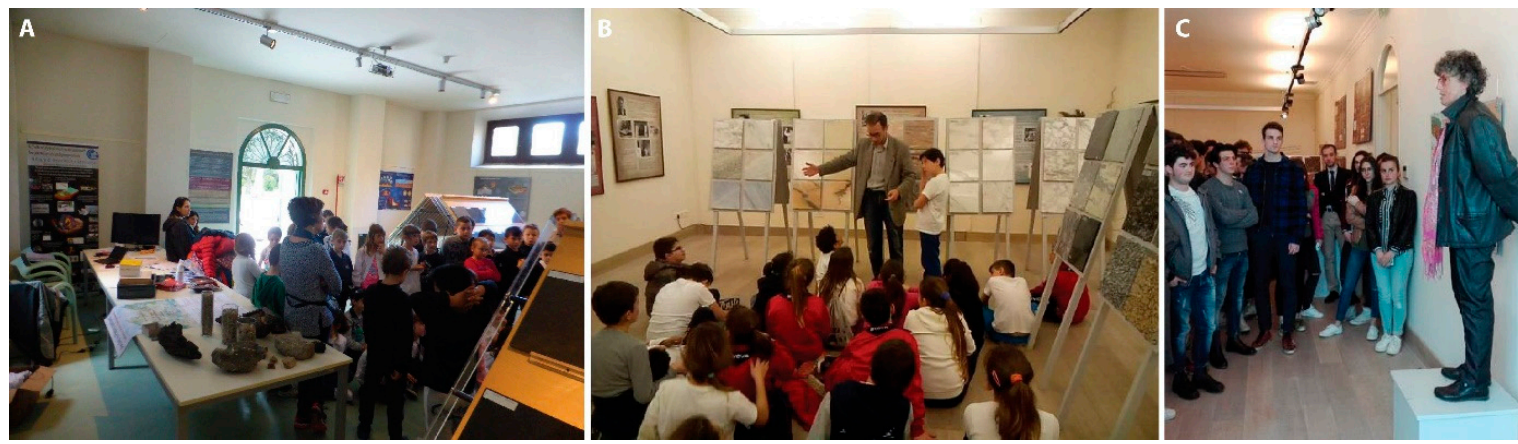

Figure 8. Although the visit was illustrated by explanatory panels, the best way to attract the more distracted public to the scientific topic was to have an explanation by an expert guide, a geologist who can interact with the public, who is able to use clearer or deeper explanations according to the target audience. (A) Villa Borbone (Viareggio, Lucca); (B,C) Villa Bertelli (Forte dei Marmi, Lucca).

The exhibition recorded almost a thousand visitors in two weeks. After this great success, the event was hosted first at Villa Bertelli (Forte dei Marmi, LU) in the framework of "Che Forte, la Scienza!"(i.e., Science is Cool!) a festival of scientific culture (800 visitors in two week) and successively at a high school in Boario Terme (Brescia, Italy).

\section{2. "Ludoteca Scientifica" Workshops}

Two workshops for children have been designed and created by IGG - CNR in collaboration with the Department of Earth Sciences of the University of Pisa (DST-UniPi). The workshops have been hosted by the XVI and XVII editions of the "Ludoteca Scientifica" (i.e., Science Toy Library) an interactive scientific exhibition promoted by the Department of Physics "Enrico Fermi" of the University of Pisa, the National Institute of Optics (CNR) and other scientific institutions and associations operating in Pisa (e.g., Ass. La Nuova Limonaia).

(1) Even the Rocks Talk. Based on the experience of the exhibition, we decided to create a more specific laboratory for schoolchildren during which, in addition to showing ornamental stone materials, it was possible to touch the rocks and explore their physical and chemical properties and the main 
geological processes through some game-experiments. By observing various rocks, the children learnt to recognize their structures and the main rock-forming minerals and to discover whether the rock formed beneath the Earth's surface by slow cooling of a magma body, or by a volcanic eruption, if it is composed of fragments of other rocks previously eroded or has been transformed under the ground following an increase in pressure and temperature. (2) The Pisa's Stones: a multidisciplinary workshop for any level of student, to understand the urban geology of Pisa and its territory by studying the macroscopic and microscopic characteristics and the main physical properties of the rocks used in the monumental building of Pisa. The workshop is accompanied by a walk through Piazza dei Miracoli (where the famous Leaning Tower is located) and the walkway on the ancient City Walls of Pisa, which has recently opened to the public, to discover their "stones" that tell of journeys, imports, plunders and local quarrying activities (Figure 9).
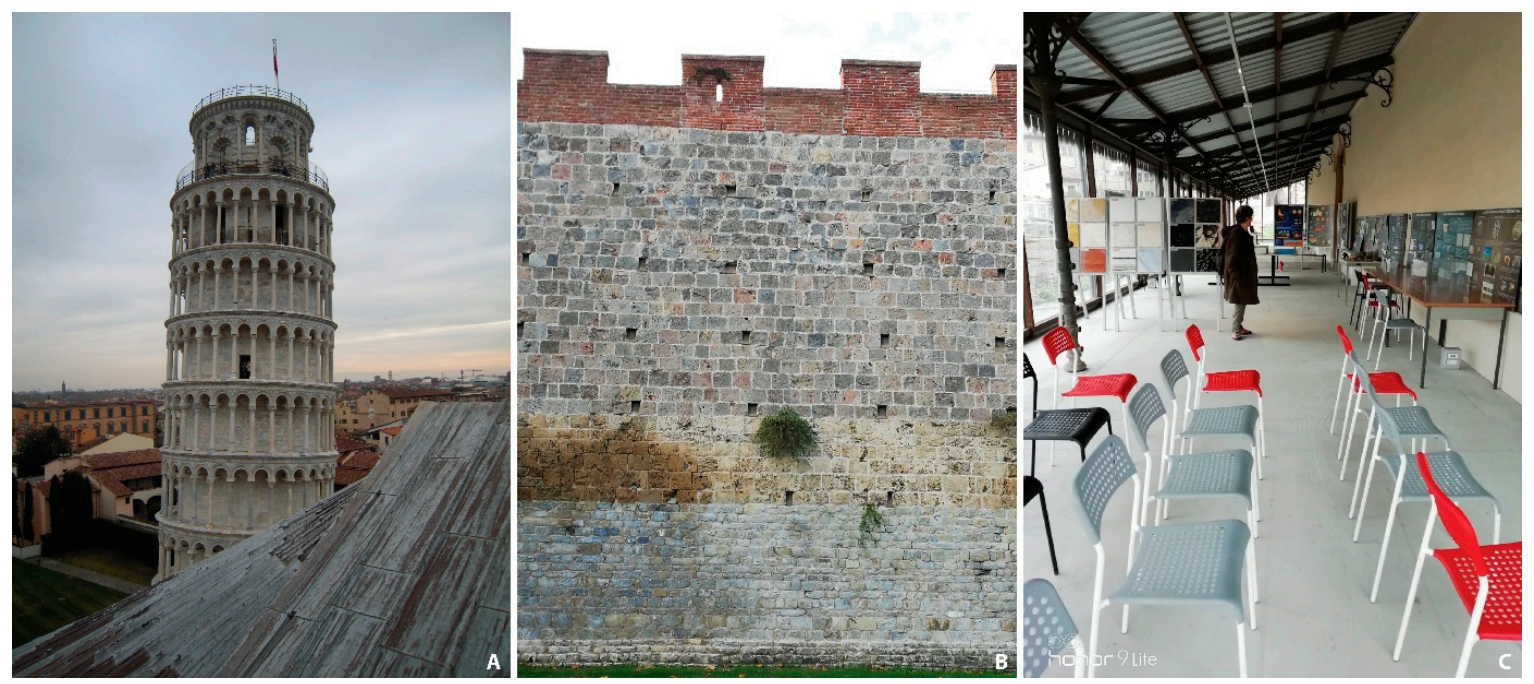

Figure 9. (A) One of the most famous monuments in the world: the Leaning Tower (Piazza dei Miracoli, Pisa), (B) a glimpse of the multilayer ancient City Walls of Pisa, (C) the workshops related to commercial stones and architecture of the city are hosted by the "Ludoteca Scientifica" at "Cittadella Galileiana" (Pisa).

In literature, there are several papers describing in detail the main stones used in Pisa [21-24] and on the medieval stones of the western Tuscany [25-31].

\section{3. "Earth Planet Week" National Program}

In the framework of "Settimana del Pianeta Terra", a national program for the diffusion and dissemination of the Earth Sciences, we organized some activities such as: (a) walking in Pisa and Lucca to recognize the stones used as building materials in the center of Pisa during the Middle Age (DST-UniPi) [31]; (b) temporary exhibition of ornamental stones at the research area of Pisa (IGG-CNR); (c) thematic conference and city walk titled: Territory, Geo-Resources and Cultural Heritage: Examples of "Urban Petrography" in Sicily and Tuscany, IGG-CNR in collaboration with the Museum of Mineralogy (DiSTeM, UniPa) (Figure 10). 

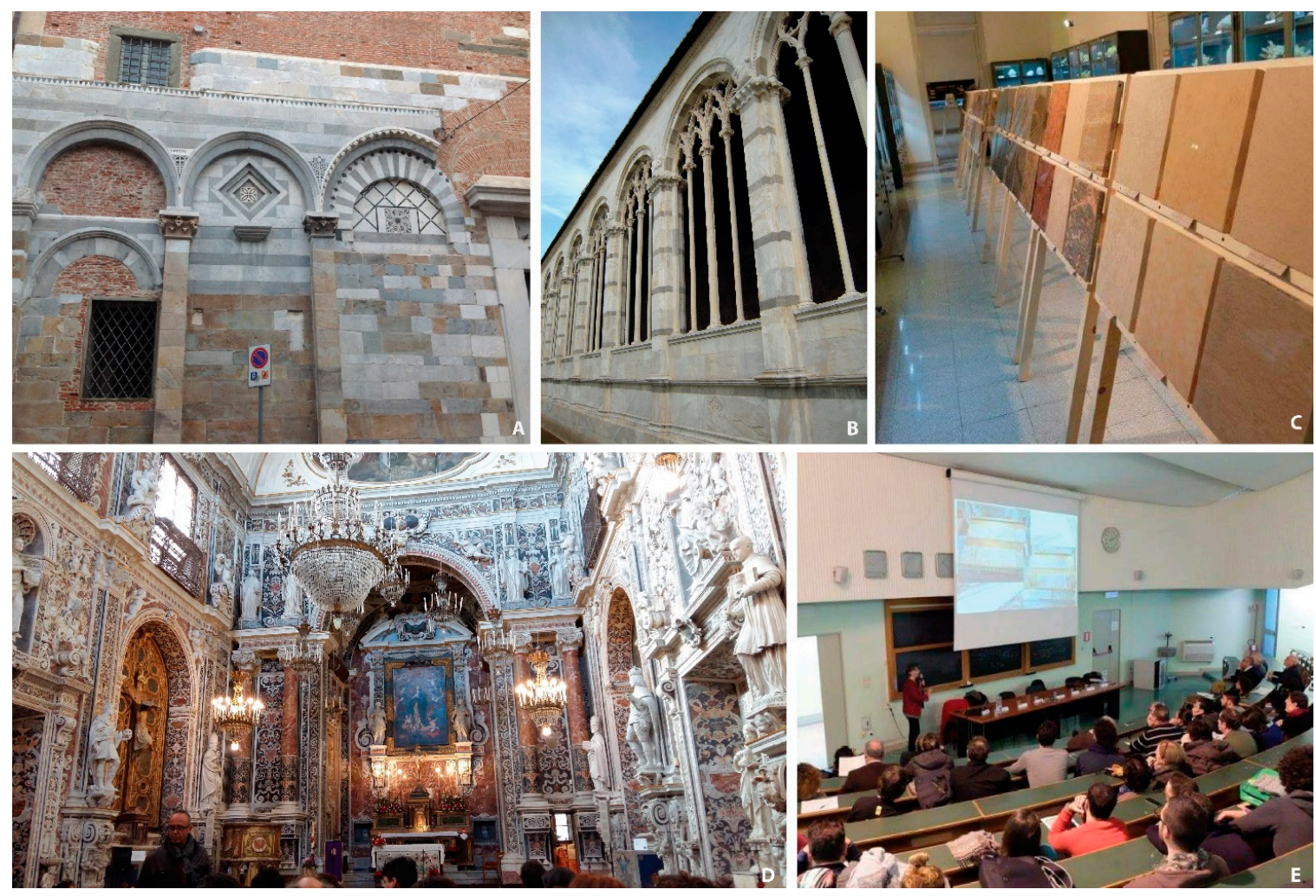

Figure 10. Some activities of "Urban Petrography" in the framework of "Settimana del Pianeta Terra": (1) a walk in the center of Pisa was organized to recognize the stones used as building materials; (A) St. Nicholas church façade shows a patchwork of Monte Pisano marble, quartzite and black limestone [31]. A marble intarsia on the façade illustrates a Fibonacci abacus [32]; (B) the Monte Pisano marbles used for building the Monumental Cemetery; (2) activities in collaboration with University of Palermo, Sicily: (C) donation of a collection of about 200 samples of ornamental stones and temporary exhibition at Museum of Mineralogy (DiSTeM, UniPa); (D) a guided tour of a baroque church (Chiesa dell'Immacolata Concezione) in Palermo to recognize the ornamental stones presented during the thematic conferences (E).

\section{4. "European Researchers' Night" International Event (Marie-Sklodowska-Curie-Actions)}

During the international "European Researchers' Night" in Tuscany [33], a "treasure hunt" for children was organized at the Villa Borbone garden (Viareggio). The young aspiring geologists were capable to identify the rocks they found while playing.

\section{5. "Alternanza Scuola-Lavoro" Ministerial Training Project}

"Alternanza Scuola-Lavoro" (i.e., School-Work Alternation) is an innovative didactic methodology established by MIUR (L. n. 53/2003, D.L. n. 77/2005) for high school students, in order to bring young people closer to the world of work, alternating training periods between school and partner companies or other organizations [4]. In the framework of this program the students (Liceo Classico "Giosuè Carducci, Viareggio, Lucca), using $10 \mathrm{~cm} \times 10 \mathrm{~cm}$ sized ornamental stone slabs, had to classify the samples assigned to them according to the commercial and geological criteria an then they had to build a small database and make an oral presentation of the project at school.

\subsection{CoRRo Project for Training Course}

CoRRo project (i.e., Know and Recognize the Rocks, acronym) (funded by Fondazione Banco del Monte di Lucca) is a training course for medium and high school teachers, which is still ongoing. 
The project aims to create a didactic collection of rock samples (hand specimen and thin section) classified and described by their origin, genesis, age, mineralogical content, scientific name and commercial name. The training course will be carried out with an innovative didactic approach based on research technologies normally used in university courses of Earth Sciences.

\section{Conclusions}

Italy represents a symbiosis between landscape and culture, between history and its artistic, architectural, monumental and museum heritage. With our experiences of scientific dissemination, we would like to bring the public closer to the Geological Heritage using both the cultural and artistic heritage and the commercial world. In order to transfer our scientific knowledge, we have experimented with different dissemination activities, and found that direct contact with an expert guide capable to modulate the language has been one of the most successful methods. The main message was that rocks carry spatial and temporal information related to geological processes. The role of a geologist, in this context, is to provide to the public, in very clear and engaging language, the tools necessary to solve the puzzle (i.e., learn to identify the most important rock-forming minerals, know their physical and chemical properties, and discover the environments in which they formed).

In our experience, the interaction of researchers from different institutions with their multidisciplinary skills has been fundamental to affirm the idea that scientific research and technological innovation are crucial to making geological and cultural heritage and knowledge easily available and widely disseminated.

In the near future, we would like to make the exhibition of the ornamental stones collection permanent. This would create a repository of rocks available for dissemination activities at all levels, shareable with other educational and research institutions that deal with scientific dissemination in our territory. The project plan is to add the microscopic description on appropriate informative panels and to conceive thematic educational workshops. Finally, the possibility of training young guides among high school or university students could be very useful.

Author Contributions: Conceptualization, C.P., S.L.F., and M.L.; Methodology, C.P., T.A., S.L.F., M.L.; Investigation, T.A., S.L., A.A., S.L.F.; Data Curation, T.A., S.L., A.A.; Writing-Original Draft, S.L.F., T.A.; Writing-Review \& Editing, S.L.F., T.A., M.L., and C.P.; Visualization, S.L.F.; Supervision, C.P., M.L.; Project Administration, C.P., M.L.; Funding Acquisition, C.P.

Funding: Bright (European Researchers' Night in Tuscany) has received funding from the European Union's Horizon 2020 research and innovation program, under grant agreement Bright $n$. 818515. CoRRo project was funded by Fondazione Banco del Monte di Lucca. Part of the ornamental stones was given by: CosMaVe Pietrasanta (LU); Centro Servizi Marmo s.c.a.r.l. - Volargne di Dolcè (VR); Sergio Chiesa - CNR, IDPA; EllebiMarmi s.r.l. - Pietrasanta (LU); Savema s.p.a. - Pietrasanta (LU); V. Fontanili s.r.l.- Carrara (MS).

Acknowledgments: The authors would like to thank for their kindly collaboration: M.M. Massai (President of "Associazione La Nuova Limonaia") Department of Physics - University of Pisa, Italy; S. Giudici (Director of "Museo degli Strumenti di Fisica" and "Ludoteca scientifica") Department of Physics -University of Pisa, Italy; S. Calabrese, L. Randazzo and G. Montana Department of Earth and Marine Science, University of Palermo, Italy; the Municipality of Forte dei Marmi (LU), Italy; the Municipality of Viareggio (LU), Italy. The authors would like to thank the three reviewers for their helpful comments on the manuscript.

Conflicts of Interest: The authors declare no conflict of interest.

\section{References}

1. King, H. Student difficulties in learning geoscience. Planet 2012, 25, 40-47. [CrossRef]

2. Geological Society of America Position Statement. The Importance of Teaching Geoscience. 2004. Available online: https://www.geosociety.org/documents/gsa/positions/pos4_TeachingEarthScience.pdf (accessed on 23 July 2019).

3. Piano Lauree Scientifiche. Available online: https://www.pianolaureescientifiche.it/ (accessed on 23 July 2019).

4. Alternanza Scuola Lavoro. Available online: http://www.istruzione.it/alternanza/ (accessed on 23 July 2019).

5. Diffusione della Cultura Scientifica. Available online: https://www.miur.gov.it/web/guest/diffusione-dellacultura-scientifica (accessed on 23 July 2019). 
6. Settimana della Scienza. Available online: https://www.miur.gov.it/web/guest/settimana-della-scienza (accessed on 23 July 2019).

7. Geological Survey of Italy (ISPRA). Available online: http://portalesgi.isprambiente.it/en/disseminationactivities (accessed on 23 July 2019).

8. European Researchers' Nights - Marie Skłodowska-Curie Actions - EU Commission. Available online: https: //ec.europa.eu/research/mariecurieactions/actions/european-researchers-night_en (accessed on 23 July 2019).

9. Settimana del Pianeta Terra. Available online: https://www.settimanaterra.org/ (accessed on 23 July 2019).

10. Associazione La Nuova Limonaia per la Diffusione della Cultura Scientifica, Tecnologica e dei Diversi rami del Sapere. Available online: http://www.lanuovalimonaia.it/ (accessed on 23 July 2019).

11. Ludoteca Scientifica. Available online: http://www.ludotecascientifica.it/ (accessed on 23 July 2019).

12. Carmignani, L.; Conti, P.; Meccheri, M.; Mancini, S.; Massa, G.; Simoncini, D.; Vaselli, L. Carta Giacimentologica dei Marmi delle Alpi Apuane, Relazione Finale; Convenzione Regione toscana e Dipartimento di Scienze della Terra, Centro di GeoTecnologie, Università di Siena: Siena, Italy, 2007.

13. Carmignani, L.; Conti, P.; Cornamusini, G.; Pirro, A. Geological map of Tuscany (Italy). J. Maps. 2013, 9, 487-497. [CrossRef]

14. ERTAG Regione Toscana. I Marmi Apuani; Nuova Grafica Fiorentina: Firenze, Italy, 1980; 126p.

15. Technological District of Marble and Ornamental Stones. Available online: http://www.distrettodelmarmo.it/ (accessed on 23 July 2019).

16. Standard UNI EN 12670:2019. Natural Stone, Terminology. Available online: http://store.uni.com/catalogo/ index.php/uni-en-12670-2019.html (accessed on 23 July 2019).

17. Horenstein, S. Building Stone Treasure Troves. Evol. Educ. Outreach 2008, 1, 520-530. [CrossRef]

18. London's Geology: Walks. Earth Science Department of University College of London. Available online: https: //www.ucl.ac.uk/earth-sciences/impact/public-engagement/londons-geology/londons-geology-walks (accessed on 23 July 2019).

19. Gambino, F.; Borghi, A.; D’Atri, A.; Gallo, L.M.; Ghiraldi, L.; Giardino, M.; Martire, L.; Palomba, M.; Perotti, L. Tourinstone: Application for mobile on ornamental stones of the city of Turin. Rend. Soc. Geol. Ital. 2017, 42, 81-84. [CrossRef]

20. Principe, C.; Landi, S.; La Felice, S. Villa Borbone. Apuo-Versilia-Produce 2016, 92, 6-8.

21. Franzini, M.; Lezzerini, M. Palazzo Gambacorti: Le pietre del paramento. In Palazzo Gambacorti a Pisa. Un Restauro in Cantiere; Electa: Milano, Italy, 1998; pp. 230-234.

22. Baracchini, C.; Pini, R.; Fabiani, F.; Ciafaloni, M.; Siano, S.; Sabatini, G.; Giamello, M.; Franzini, M.; Lezzerini, M. The pilot restoration yard of the Church of San Frediano: Results of a multidisciplinary study. In Lasers in the Conservation of Artworks; Dickmann, K., Fotakis, C., Asmus, J.F., Eds.; Springer Proceedings in Physics; Springer: Berlin/Heidelberg, Germany, 2005; Volume 100, pp. 191-197.

23. Lezzerini, M. Mappatura delle pietre presenti nella facciata della chiesa di San Frediano (Pisa, Italia). Atti Soc. Tosc. Sci. Nat. Mem. Ser. A 2005, 110, 43-50.

24. Lezzerini, M.; Antonelli, F.; Columbu, S.; Gadducci, R.; Marradi, A.; Miriello, D.; Parodi, L.; Secchiari, L.; Lazzeri, A. Cultural heritage documentation and conservation: Three-dimensional (3D) laser scanning and geographical information system (GIS) techniques for thematic mapping of façade stonework of St. Nicholas church (Pisa, Italy). Int. J. Archit. Herit. 2016, 10, 9-19. [CrossRef]

25. Franzini, M. Le pietre toscane nell'edilizia medievale della città di Pisa. Mem. Soc. Geol. Ital. 1993, 49, 233-244.

26. Franzini, M.; Lezzerini, M. Le pietre dell'edilizia medievale pisana e lucchese (Toscana occidentale). 2-I calcari selciferi del Monte Pisano. Atti Soc. Tosc. Sci. Nat. Mem. Ser. A 1998, 105, 1-8.

27. Franzini, M.; Lezzerini, M. The stones of medieval buildings in Pisa and Lucca (Western Tuscany, Italy). 4-B Agnano breccias from Mt. Pisano. Eur. J. Mineral. 2002, 14, 447-451. [CrossRef]

28. Franzini, M.; Lezzerini, M. The stones of medieval buildings in Pisa and Lucca provinces (western Tuscany, Italy). 1-The Monte Pisano marble. Eur. J. Mineral. 2003, 15, 217-224. [CrossRef]

29. Franzini, M.; Lezzerini, M.; Mannela, L. The stones of medieval buildings in Pisa and Lucca (Western Tuscany, Italy). 3-Green and white-pink quartzites from Mt. Pisano. Eur. J. Mineral. 2001, 13, 187-195. [CrossRef]

30. Franzini, M.; Gioncada, A.; Lezzerini, M. Le pietre dell'edilizia medievale pisana e lucchese (Toscana occidentale). 5-La Maiolica e il Nummulitico della Bassa Valle del fiume Serchio. Atti Soc. Tosc. Sci. Nat. Mem. Ser. A 2007, 112, 9-19. 
31. Lezzerini, M.; Pagnotta, S.; Legnaioli, S.; Palleschi, V. Walking in the Streets of Pisa to Discover the Stones Used in the Middle Ages. Geoheritage 2019, 1-11. [CrossRef]

32. Armienti, P. The medieval roots of modern scientific thought. A Fibonacci abacus on the façade of the church of San Nicola in Pisa. J. Cult. Herit. 2016, 17, 1-6. [CrossRef]

33. European Researchers' Night in Tuscany: BRIGHT Project (Brilliant Researchers Impact on Growth Health and Trust in Research). Available online: http://www.bright-toscana.it/bright/ (accessed on 23 July 2019).

(C) 2019 by the authors. Licensee MDPI, Basel, Switzerland. This article is an open access article distributed under the terms and conditions of the Creative Commons Attribution (CC BY) license (http://creativecommons.org/licenses/by/4.0/). 